\title{
Double superior vena cava: Two cases in Thai cadavers
}

Sitthichai Iamsaard, Pipatphong Kanla, Channarong Arunyanart

Department of Anatomy, Faculty of Medicine, Khon Kaen University, Khon Kaen, Thailand
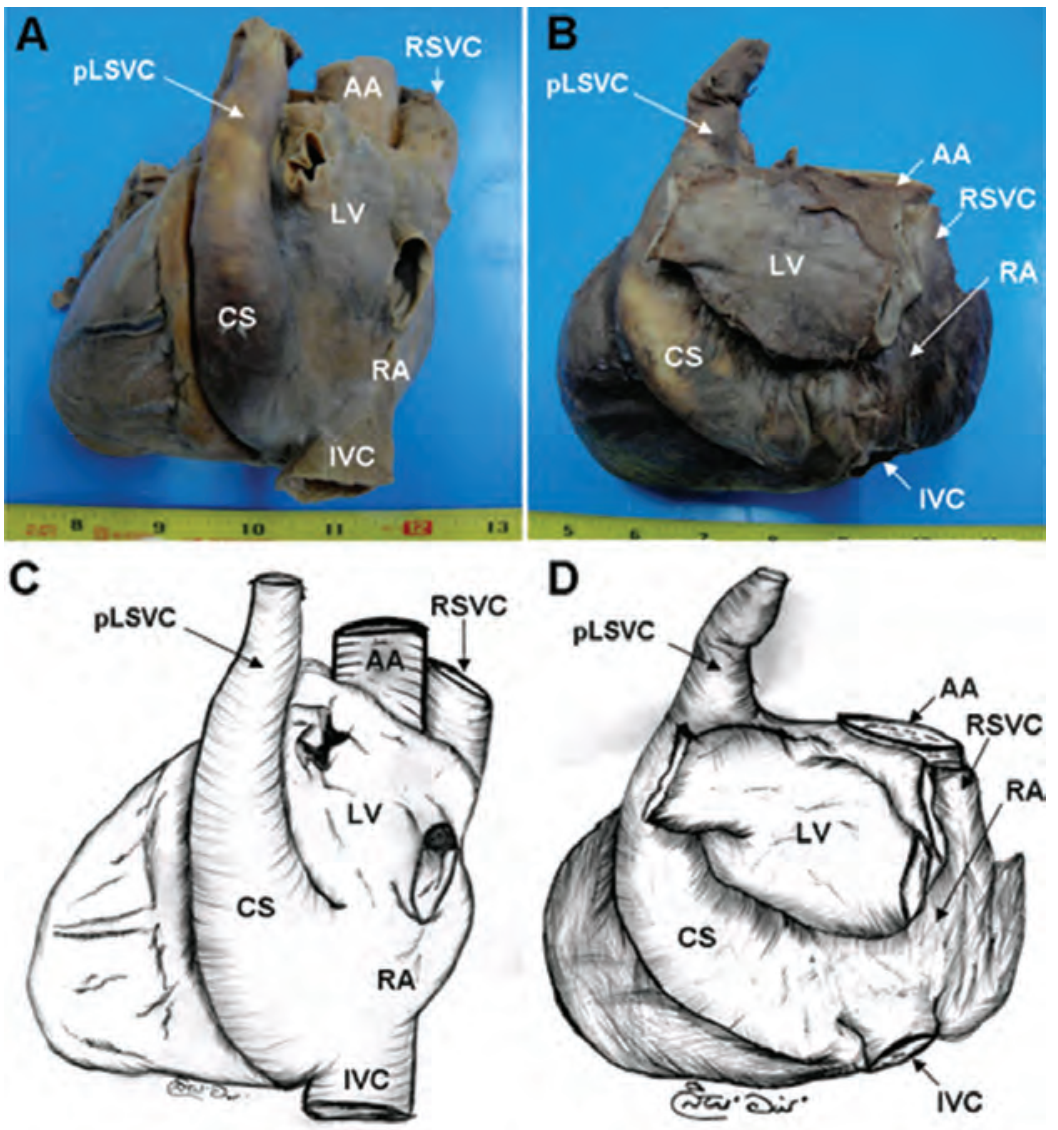

Figure 1 Photographs ( $A$; case 1 and $B$; case 2) and illustrations of Figure $1 A(C)$ and Figure $1 B(D)$ showing double superior vena cava: right connected to right atrium and left to the coronary sinus. pLSVC: persistent left superior vena cava; RSVC; right superior vena cava; CS: coronary sinus; LV: left ventricle; RA: right atrium; AA ascending aorta; IVC: inferior vena cava. In both cases, the venous drainage pattern was similar as shown in Figure 2. It was investigated that the right or left brachiocephalic vein drained into its own superior vena cava, i.e. RSVC or pLSVC (Figure 2). Additionally, RSVC joined with an azygos vein and drained into the right atrium directly. No defects of inferior vena cava and/or venous connections between RSVC and pLSVC were observed in either case. 


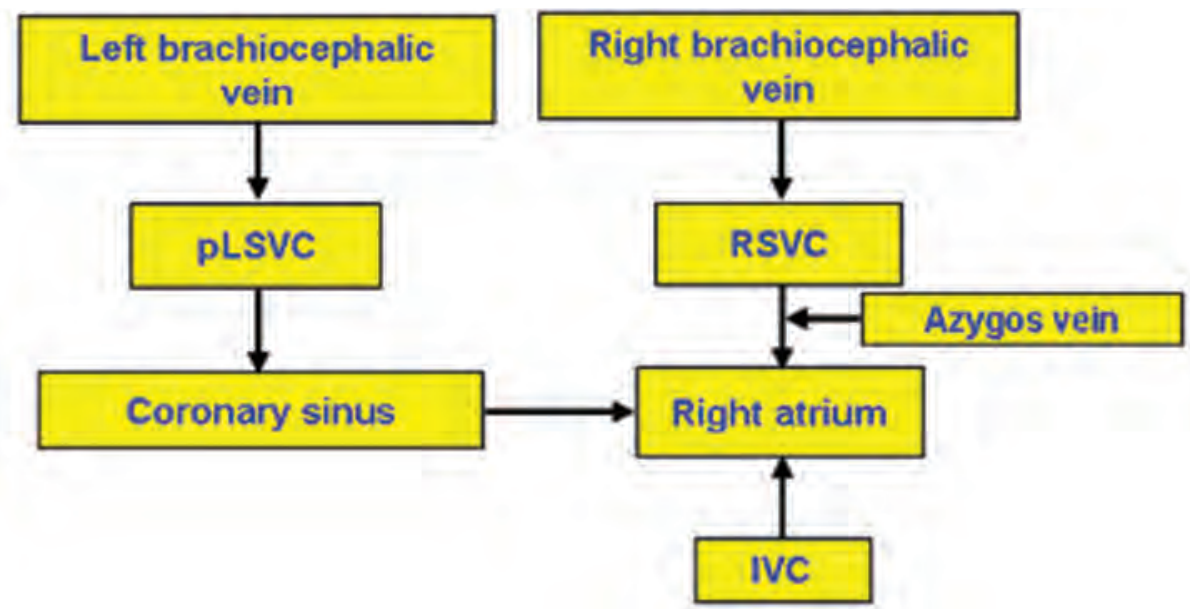

Figure 2 Flowchart showing the venous drainage pattern of double superior vena cava (posterior view) in the present report (pLSVC: persistent left superior vena cava; RSVC: right superior vena cava; IVC: inferior vena cava). Note: right or left brachiocephalic veins drain into individual-sided SVC and pLSVC drains into right atrium via coronary sinus while RSVC including azygos vein is connected to the right atrium directly. As previously described (3), the two cases demonstrated in this report are of Type I-R. To our knowledge, this is the first report demonstrating the DSVC in the Thai population $(0.42 \% ; 2$ found cases from 480$)$.

The coexistence of persistent left superior vena cava (pLSVC) and right superior vena cava (RSVC) is also called "double superior vena cava (DSVC)". Although some cases of DSVC have been reported in many populations (1-3), the DSVC in Thais is very rare. We report two cases of DSVC observed in 480 Thai cadavers. We found two cases of DSVC: in a 18 year-old cadaver, death by driving (Figure 1A) and in a 75 year-old cadaver, death by heart failure (Figure 1B).

Key words: Double superior vena cava, Persistent left superior vena cava, Right superior vena cava, Coronary sinus, Right atrium.

Received: 3 October 2013; Accepted: 27 November 2013

Authors' contributions: Conception and design: SI; Acquisition, analysis and interpretation of data's: SI, PK, CA; Drafting the article: SI; Revising it critically for important intellectual content: SI.

Conflict of interest: The authors declare that they have no conflict of interest.

Copyright (C) 2014 by Academy of Sciences and Arts of Bosnia and Herzegovina. E-mail for permission to publish: amabih@anubih.ba
Corresponding author:

Sitthichai Iamsaard

Department of Anatomy, Faculty of Medicine

Khon Kaen University

123 Mitraparp Road, Amphoe Muang

Khon Kaen 40002, Thailand

Iamsaard_sitt@yahoo.com

Tel.: + 664336 3212; Fax.: + 6643363212

\section{References}

1. Miraldi F, Carbone I, Ascarelli A, Barretta A, D'Angeli I. Double superior vena cava: right connected to left atrium and left to coronary sinus. Int J Cardiol. 2009;131(2):78-80.

2. Ratliff HL, Yousufuddin M, Lieving WR, Watson BE, Malas A, Rosencrance G, et al. Persistent left superior vena cava: case reports and clinical implications. Int J Cardiol. 2006;113(2):242-6.

3. Uemura M, Suwa F, Takemura M, Toda I, Morishita A. Classification of persistent left superior vena cava considering by bilateral superior venae cavae, anastomotic ramus between superior venae cavae, and azygos venous system. Anatomical Sci Int. 2012; 87(4):212-22. 